\title{
Anesthetic Management of Endovascular Coiling of Intracranial Aneurysm in a Patient with Uncorrected Ebstein's Anomaly
}

\author{
Sangeetha RP ${ }^{1}$ Radhakrishnan $\mathrm{M}^{1}$ Arvindha $\mathrm{HR}^{2}$
}

Address for correspondence Sangeetha RP, MD, DNB, DM, Neuroanaesthesiology, Department of Neuroanesthesiology and Neurocritical Care, Third floor, Faculty Block, National Institute of Mental Health and Neurosciences, Bengaluru 560029, India (e-mail: sangeetharp14@gmail.com).
Ebstein's anomaly is a rare congenital cardiac disease with dysplastic tricuspid valves, resulting in a wide spectrum of clinical manifestations, ranging from asymptomatic state to severe congestive cardiac failure (CCF). ${ }^{1}$ This report describes such a patient who underwent endovascular coiling of an intracranial cerebral aneurysm under general anesthesia. Written informed consent was obtained from the patient before writing this manuscript. A 40-year-old female patient, weighing $50 \mathrm{~kg}$, presented with a history of right-sided frontal headache and left upper limb weakness of 20 days duration. She was diagnosed to have systemic hypertension and Ebstein's anomaly and was on treatment with calcium channel blockers, beta-blockers, antiplatelet, and anticoagulant for the past 10 years. She had no symptoms of chest pain, palpitations, breathlessness, cyanotic spells, or easy fatiguability during the current visit. Diagnostic workup for her presenting symptoms included digital subtraction angiography of the cerebral vessels that revealed a right middle cerebral artery aneurysm measuring $5 \times 2.5 \times$ $2.78 \mathrm{~mm}$. Systemic examination was unremarkable except for a low baseline peripheral arterial oxygen saturation $\left(\mathrm{SpO}_{2}\right)$ of $88 \%$ at room air and pansystolic murmur of Levine grade 3 on auscultation in tricuspid area, with no signs suggestive of CCF. Her investigations were unremarkable except for electrocardiogram (ECG) that showed tall broad P waves in all leads. Transthoracic echocardiogram showed severe tricuspid regurgitation (TR), dilated right atrium, and atrialized right ventricle. Patent foramen ovale (PFO) with right to left shunt was present with good biventricular function and pulmonary arterial systolic pressure of $25 \mathrm{~mm} \mathrm{Hg}$.

Our anesthetic technique was tailored to ensure a preserved normal sinus rhythm with optimal preload and afterload. Before anesthetic induction, intravenous (IV) and intra-arterial access were secured under local anesthesia. Baseline arterial blood gas at room air revealed normal acidbase status with oxygen partial pressure of $62.9 \mathrm{~mm} \mathrm{Hg}$. Monitoring included ECG, invasive blood pressure, $\mathrm{SpO}_{2}$, capnography, esophageal temperature, and neuromuscular transmission. Monitoring of regional cerebral oxygen saturation $\left(\mathrm{rSCO}_{2}\right)$ was done using near infra-red spectroscopy-based cerebral oximetry (Nonin Equanox 7600; Nonin Medical Inc., Plymouth, Massachusetts, United States). Sensors were placed bilaterally on forehead, $2 \mathrm{~cm}$ above the eyebrow, as per the manufacturer's instructions, ensuring that it did not interfere with image acquisition. Baseline $\mathrm{rScO}_{2}$ (at room air) were 61 and $59 \%$ on the left and right side, respectively. Preoxygenation with $100 \%$ oxygen improved $\mathrm{SpO}_{2}$ to $92 \%$ without any change in $\mathrm{rScO}_{2}$ values. Hemodynamic stability during induction was ensured with titrated doses of IV fentanyl up to100 $\mu$ g and propofol $100 \mathrm{mg}$. Stress response to intubation was controlled with IV lignocaine $60 \mathrm{mg}$. Vecuronium $8 \mathrm{mg}$ was administered IV to facilitate tracheal intubation. Anesthesia was maintained with oxygen: nitrous oxide mixture with a fraction of inspired oxygen of 0.5 and sevoflurane titrated to a minimum alveolar concentration of 0.8 to 1.0 along with intermittent boluses of vecuronium to maintain patient immobility throughout the procedure. Patient's lungs were mechanically ventilated without positive end expiratory pressure to maintain an end-tidal $\mathrm{CO}_{2}$ of 30 to $32 \mathrm{~mm} \mathrm{Hg}$. IV fluids were administered through a fluid warmer, titrated to keep the systolic pressure variation (SPV) at around $10 \mathrm{~mm} \mathrm{Hg}$. A liter of crystalloid was administered during the 3-hour-procedure. Care was taken to avoid air bubbles in the fluid circuit to prevent paradoxical air embolism. Systemic anticoagulation was maintained with intermittent boluses of heparin to prevent thromboembolic complications. There were two transient episodes of peripheral arterial oxygen desaturation $\left(\mathrm{SpO}_{2}\right.$ fall to $\left.70 \%\right)$ with neither of these events accompanied by changes in $\mathrm{rScO}_{2}$. These episodes were transient and reverted spontaneously. $\mathrm{rSCO}_{2}$ remained at 60 and $58 \%$ on the left and right side, respectively, during periods of arterial desaturation. Our initial suspicion was pulmonary embolism with elevated pulmonary artery pressures
DOI https://doi.org/ $10.1055 / \mathrm{s}-0039-1685249$ ISSN 2348-0548.
License terms

()(1) $\Theta \circledast$ 
causing desaturation. However, airway pressures, end-tidal $\mathrm{CO}_{2}$, and hemodynamics were within normal range and the episode was very transient lasting a minute. Arterial blood gas analysis done at the time of $\mathrm{SpO}_{2}$ fall was also within normal limits. At the end of the procedure, patient had an optimal recovery.

In this case report, we highlight the utility of cerebral oximetry, which is rarely reported during the endovascular management of cerebral aneurysm in a patient with Ebstein's anomaly. ${ }^{2}$ Our patient had an intracardiac right to left shunt due to severe TR and PFO, which explains the low baseline $\mathrm{SpO}_{2}$. Cyanotic spells can be triggered by events that augment right atrial pressures, namely hypercarbia, hypoxia, hypothermia, and acidosis. We maintained normothermia using the fluid warmer and titrated ventilation by monitoring both systemic arterial and $\mathrm{rScO}_{2}$, end-tidal capnometry, and intermittent arterial blood gas analyses. As she was clinically asymptomatic despite a low baseline $\mathrm{SpO}_{2}$, we used $\mathrm{rScO}_{2}$ to monitor regional oxygenation status. Interventional neuroradiological procedures can result in cerebral embolism due to repeated flushing, further justifying monitoring of $\mathrm{rScO}_{2}$ in this patient. As both fluid deficits and overload can compromise cardiac function in this patient, IV fluids were titrated to maintain the SPV (the patient had sinus rhythm and mechanically ventilated). Heparinized saline to flush the arterial sheath was also kept to the minimum (1 L). Advanced hemodynamic monitoring (e.g., transesophageal echocardiography, invasive cardiac output monitor) could have helped us in providing more information on cardiac function, but nonavailability of these monitors in the intervention suite precluded us from using these monitors. These monitors should be preferred if one has an access to them. Nitrous oxide can aggravate the size of embolized air and is better avoided. Due to nonavailability of medical air facility in our radiology suite and considering the deleterious effects of prolonged $100 \%$ oxygen administration, nitrous oxide was administered with $\mathrm{rScO}_{2}$ monitoring. Intraprocedural supraventricular and ventricular arrhythmias are frequent in patients with Ebstein's anomaly, mandating continuation of beta-blockers as done in this patient. Anticoagulation with heparin is usually reversed with protamine, which was avoided in this patient for fear of an allergic reaction predisposing to pulmonary arterial hypertension, especially in the context of elevated and high normal right atrial and pulmonary pressures, respectively. Femoral catheter was hence removed 24 hours later after deploying the vascular closure device.

This case report emphasizes the need for understanding the pathophysiology, anticipation of, and vigilance for potential complications during the anesthetic management of neurointerventional procedures in patients with Ebstein's anomaly. Advanced cerebral monitoring helps titrating the ventilatory and hemodynamic parameters during the management of such challenging scenarios.

\section{Conflict of Interest}

None declared.

\section{References}

1 Ross FJ, Latham GJ, Richards M, Geiduschek J, Thompson D, Joffe D. Perioperative and anesthetic considerations in Ebstein's anomaly. Semin Cardiothorac Vasc Anesth 2016;20(1):82-92

2 Xin X, Tang S, Wang L, et al. Anesthetic considerations of an emergency decompressive craniotomy complicated with Ebstein's anomaly and atrial septal defect. Chin Med J (Engl) 2011;124(4):615-617 